\title{
Normal Platelet Activation Profile in Patients with Peripheral Arterial Disease on Aspirin
}

Citation for published version (APA):

van Geffen, J. P., Kleinegris, M-C., Verdoold, R., Baaten, C. C. F. M. J., Cosemans, J. M. E. M., Clemetson, K. J., ten Cate, H., Roest, M., de Laat, B., \& Heemskerk, J.'W. M. (2015). Normal Platelet Activation Profile in Patients with Peripheral Arterial Disease on Aspirin. Thrombosis Research, 135(3), 513-520. https://doi.org/10.1016/j.thromres.2014.12.029

Document status and date:

Published: 01/03/2015

DOI:

10.1016/j.thromres.2014.12.029

Document Version:

Publisher's PDF, also known as Version of record

Document license:

Taverne

Please check the document version of this publication:

- A submitted manuscript is the version of the article upon submission and before peer-review. There can be important differences between the submitted version and the official published version of record.

People interested in the research are advised to contact the author for the final version of the publication, or visit the DOI to the publisher's website.

- The final author version and the galley proof are versions of the publication after peer review.

- The final published version features the final layout of the paper including the volume, issue and page numbers.

Link to publication

\footnotetext{
General rights rights.

- You may freely distribute the URL identifying the publication in the public portal. please follow below link for the End User Agreement:

www.umlib.nl/taverne-license

Take down policy

If you believe that this document breaches copyright please contact us at:

repository@maastrichtuniversity.nl

providing details and we will investigate your claim.
}

Copyright and moral rights for the publications made accessible in the public portal are retained by the authors and/or other copyright owners and it is a condition of accessing publications that users recognise and abide by the legal requirements associated with these

- Users may download and print one copy of any publication from the public portal for the purpose of private study or research.

- You may not further distribute the material or use it for any profit-making activity or commercial gain

If the publication is distributed under the terms of Article $25 \mathrm{fa}$ of the Dutch Copyright Act, indicated by the "Taverne" license above, 
Regular Article

\title{
Normal Platelet Activation Profile in Patients with Peripheral Arterial Disease on Aspirin ${ }^{\text {th }}$
}

\author{
Johanna P. van Geffen ${ }^{a}$, Marie-Claire Kleinegris ${ }^{a}$, Remco Verdoold ${ }^{a}$, Constance C.F.M.J. Baaten ${ }^{a}$, \\ Judith M.E.M. Cosemans ${ }^{\text {a }}$, Kenneth J. Clemetson ${ }^{b}$, Hugo ten Cate ${ }^{\text {a }}$, Mark Roest ${ }^{c, d}$, \\ Bas de Laat ${ }^{\mathrm{d}}$, Johan W.M. Heemskerk ${ }^{\mathrm{a}, *}$ \\ a Departments of Biochemistry and Internal Medicine, Cardiovascular Research Institute Maastricht (CARIM), Maastricht University Medical Centre, Maastricht, The Netherlands \\ ${ }^{\mathrm{b}}$ Department of Haematology, Inselspital, University of Bern, $\mathrm{CH}-3010$ Bern, Switzerland \\ c Department of Clinical Chemistry and Haematology, University Medical Centre, Utrecht The Netherlands \\ d Synapse B.V., Maastricht University, Maastricht, The Netherlands
}

\section{A R T I C L E I N F O}

\section{Article history:}

Received 17 November 2014

Received in revised form 22 December 2014

Accepted 30 December 2014

Available online 6 January 2015

\begin{abstract}
A B S T R A C T
Background: Peripheral arterial disease (PAD) is a progressive vascular disease associated with a high risk of cardiovascular morbidity and death. Antithrombotic prevention is usually applied by prescribing the antiplatelet agent aspirin. However, in patients with PAD aspirin fails to provide protection against myocardial infarction and death, only reducing the risk of ischemic stroke. Platelets may play a role in disease development, but this has not been tested by proper mechanistic studies. In the present study, we performed a systematic evaluation of platelet reactivity in whole blood from patients with PAD using two high-throughput assays, i.e. multiagonist testing of platelet activation by flow cytometry and multi-parameter testing of thrombus formation on spotted microarrays.

Methods: Blood was obtained from 40 patients (38 on aspirin) with PAD in majority class IIa/IIb and from 40 agematched control subjects. Whole-blood flow cytometry and multiparameter thrombus formation under highshear flow conditions were determined using recently developed and validated assays.

Results: Flow cytometry of whole blood samples from aspirin-treated patients demonstrated unchanged high platelet responsiveness towards ADP, slightly elevated responsiveness after glycoprotein VI stimulation, and decreased responsiveness after PAR1 thrombin receptor stimulation, compared to the control subjects. Most parameters of thrombus formation under flow were similarly high for the patient and control groups. However, in vitro aspirin treatment caused a marked reduction in thrombus formation, especially on collagen surfaces. When compared per subject, markers of ADP- and collagen-induced integrin activation (flow cytometry) strongly correlated with parameters of collagen-dependent thrombus formation under flow, indicative of a common, subject-dependent regulation of both processes.

Conclusion: Despite of the use of aspirin, most platelet activation properties were in the normal range in wholeblood from class II PAD patients. These data underline the need for more effective antithrombotic pharmacoprotection in PAD.
\end{abstract}

(c) 2015 Elsevier Ltd. All rights reserved.

\section{Introduction}

Peripheral arterial disease (PAD) is a systemic vascular disorder with manifestations of atherosclerosis in particular in the lower extremities, resulting in obstruction of the arterial blood flow, and strongly associated with cardiovascular events [1-3]. In the Western world, a

\footnotetext{
Funding: The authors thank the Centre for Translational Molecular Medicine (CTMM), Innovative Coagulation Diagnostics, and the Cardiovascular Centre (HVC), Maastricht University Medical Centre, for financial support. The funders had no role in study design, data collection and analysis, decision to publish, or preparation of the manuscript.

* Corresponding author at: Dept. of Biochemistry, CARIM, Maastricht University, P.O. Box 616, 6200 MD Maastricht, the Netherlands. Tel.: + 31433881671.

E-mail address: jwm.heemskerk@maastrichtuniversity.nl (J.W.M. Heemskerk).
}

considerable part of the elderly population appears to have characteristics of PAD, albeit the affected subjects often remain asymptomatic [4,5]. Symptomatic patients, already at an early stage (Fontaine class IIa/IIb), suffer from intermittent claudication and cannot walk a long distance without feeling pain [2]. At later stages (Fontaine classes III/IV), PAD patients progressively suffer from chronic and critical leg ischemia [2].

While it is recognized that systemic atherosclerosis is one of the underlying diseases of PAD, the pathophysiology of this disease is still not well understood. One of the early concepts was that aberrant coagulation, inflammation and platelet activity in these patients lead to ongoing thrombogenesis in the lower extremities [6]. In agreement with this, markers of systemic coagulation such as levels of D-dimer are increased in patients with PAD, but it is unclear whether this also reflects causality 
[7-10]. Consistently, also plasma levels of the inflammation marker Creactive protein are elevated $[10,11]$. There is also ample evidence in the literature for increased platelet activation and aggregation in PAD [12-15], although this is not an undisputed finding [8,16,17]. The role of platelets in PAD may indeed be complex. On the one hand, antiplatelet treatment with aspirin, inhibiting thromboxane formation, is a standard therapy for PAD patients, with inhibitors of the platelet P2 $\mathrm{Y}_{12}$ receptors (clopidogrel, prasugrel) as effective alternatives [18]. On the other hand, there is evidence that in these patients, even after aspirin treatment, platelet functions remain high [19], platelet-monocyte aggregates are still formed [20], and platelet cleavage products such as soluble CD40L accumulate in the plasma [21]. Since PAD in many patients is a progressive disease with high cardiovascular risk, the question is whether residual high on-treatment platelet activity may contribute to the disease progression.

In recent years, a number of whole-blood based tests for detailed and overall platelet phenotyping in bleeding and thrombosis have been developed and validated. Plate-wells based flow cytometric tests allow simultaneous determination of key platelet responses, i.e. fibrinogen binding (integrin $\alpha_{\mathrm{II}} \beta_{3}$ activation) and secretion (P-selectin exposure) in response to a panel of receptor agonists [22,23]. Such flow cytometric tests are advantageous in detecting changed platelet activation in thrombotic patients [24]. Furthermore, flow chamber devices for whole-blood perfusion over a thrombogenic surface like collagen have appeared to be highly valuable in detecting a loss or gain of platelet function, supporting their use as ex vivo assays reflecting arterial thrombus formation [25-27]. Recently, we have extended this method into a multi-parameter platelet function test to assess thrombus formation on arrays of microspotted platelet-adhesive surfaces [28].

In the present paper, we used both high-throughput whole-blood assays, i.e. multi-agonist testing of platelet activation by flow cytometry and multi-parameter testing of thrombus formation on microarray spots, for detailed evaluation of the platelets in patients with PAD receiving aspirin. The data show that platelet function in these patients is in general high despite aspirin treatment, thus not pointing to a decreased prothrombotic propensity.

\section{Methods}

\section{Patients and Controls}

Included were 40 patients with established PAD. Patients were selected based on a decrease in the ankle brachial index $<0.9[29,30]$ and most of them suffered from a stage IIa/IIb disorder according to the Fontaine classification [2]. As a control group, 40 healthy control subjects were included with similar age and gender. Fitness (i.e., nondisease state) of the control subjects was assessed with the Edinburgh claudication questionnaire [31]. Medication use was checked in all patient and control subjects by personal interview. Exclusion criteria for patients and controls were: proved coagulation or chronic inflammatory disorders, active infection, malignancy, anti-phospholipid syndrome, pregnancy and/or prescribed antiplatelet or anticoagulant medicines other than aspirin. The study was approved by the Medical Ethics Committee of the Maastricht University Medical Center. All patients and healthy subjects gave written informed consent for participation according to the declaration of Helsinki.

\section{Blood Collection}

Blood was drawn from subjects in resting condition, and collected into $10 \mathrm{~mL}$ tubes containing 3.2\% trisodium citrate. Portions of the whole-blood were directly used for flow cytometric and flow chamber assays. Separate blood samples were collected into $4 \mathrm{~mL}$ EDTA tubes (BD Vacutainer, Breda, the Netherlands) for determination of haemoglobin and blood cell counts with a Sysmex XN-9000 analyzer (Kobe, Japan).

\section{Whole-Blood Flow Cytometry}

Agonist-induced platelet activation was assessed by an optimized and validated test using diluted whole-blood samples without centrifugation steps [22]. In brief, a 96-well plate was thawed, containing phycoerythrin (PE)-conjugated anti-P-selectin mAb (BD 555524, Pharmingen, Franklin Laker, NJ) and FITC-conjugated anti-fibrinogen Ab (F011102, Dako, Denmark) together with varying concentrations of ADP (01897-1G, Sigma-Aldrich, Zwijndrecht, the Netherlands), collagen peptide (CRP-xl, Cambridge University, UK, a generous gift) [22] or TRAP-6 (H2936.0025, Bachem, Weil am Rein, Germany); volume was $50 \mu \mathrm{L}$ in buffer A (10 mM Hepes, $150 \mathrm{mM} \mathrm{NaCl}, 5 \mathrm{mM} \mathrm{KCl}, 1 \mathrm{mM}$ $\mathrm{MgCl}_{2}$ ). Activations were started by adding to each well $5 \mu \mathrm{L}$ of blood, while mixing. Final agonist concentrations were: 0.1-2.7 $\mu \mathrm{M}$ ADP, 5$135 \mathrm{ng} / \mathrm{mL}$ collagen peptide or 0.4-3.2 $\mu \mathrm{M}$ TRAP-6. A separate row did not contain platelet agonists and served as vehicle. After 20 minutes of activation, $500 \mu \mathrm{L}$ fixation solution $(0.9 \% \mathrm{NaCl}, 0.2 \%$ formaldehyde) was added to each well. Integrin activation and P-selectin expression in platelets were analyzed on an Accuri C6 flow cytometer (Becton and Dickinson, CA; 10,000 events), as described [24]. Data are represented as mean fluorescence intensities.

\section{Whole-Blood Thrombus Formation on Microspots}

Whole-blood thrombus formation under flow was investigated with the Maastricht flow chamber (depth $50 \mu \mathrm{m}$, width $3 \mathrm{~mm}$, length $30 \mathrm{~mm}$ ), employing a newly developed and validated multi-parameter assay in combination with three microspots [28]. Where indicated, control blood samples were pre-incubated with lysine acetylsalicylate for 10 minutes at $37{ }^{\circ} \mathrm{C}(100 \mu \mathrm{M}$, Aspegic, Sanofi, Gouda, the Netherlands). Microspots on glass coverslips were prepared by applying $0.5 \mu \mathrm{L}$ collagen type I Horm $(100 \mu \mathrm{g} / \mathrm{mL}$ ), von Willebrand factor (vWF, $50 \mu \mathrm{g} / \mathrm{mL}$ ) combined with CLEC-2 agonist rhodocytin $(250 \mu \mathrm{g} / \mathrm{mL})$, and vWF plus fibrinogen $(250 \mu \mathrm{g} / \mathrm{mL})$. Sources of microspots were as described before [32]. Citrate whole-blood perfusion was at arterial wall-shear rate of $1600 \mathrm{~s}^{-1}$ for 3.5 minutes. Brightfield images were taken from all three microspots, while chambers were stained with Alexa Fluor (AF) 647-labeled annexin A5 (1:200, A23204, Life Technology, Eugene, OR) and FITC-labelled antiP-selectin mAb (1:40, A07790, Beckman Coulter, Woerden, the Netherlands) in buffer B (10 mM Hepes, $136 \mathrm{mM} \mathrm{NaCl}, 2.7 \mathrm{mM} \mathrm{KCl}$, $2 \mathrm{mM} \mathrm{MgCl}_{2}, 2 \mathrm{mM} \mathrm{CaCl}_{2}, 0.1 \%$ glucose, $0.1 \%$ bovine serum albumin, $5 \mathrm{U} /$ $\mathrm{mL}$ fragmin (low-molecular weight heparin) (RVG20607, Pfizer, Capelle $\mathrm{a} / \mathrm{d}$ IJssel) and $1 \mathrm{U} / \mathrm{mL}$ unfractionated heparin (1760 U/mL, $125 \mathrm{~K} 1336$, Sigma), $\mathrm{pH}$ 7.45). The anticoagulants were added to all $\mathrm{Ca}^{2+}$-containing perfusion buffers to prevent thrombin and fibrin generation. Images of FITC and AF647 fluorescence were captured after a short rinse with buffer

Table 1

Baseline characteristics of control subjects and PAD patients. Data are represented as medians (ranges).

\begin{tabular}{|c|c|c|c|}
\hline Subject characteristics & Controls & Patients & $P$ \\
\hline \multicolumn{4}{|l|}{ General } \\
\hline Age, years & $67(60-71)$ & $67(65-72)$ & \\
\hline Male gender, $n$ & $22 / 40$ & $24 / 40$ & \\
\hline Body mass index, $\mathrm{kg} / \mathrm{m}^{2}$ & $26(23.4-27.8)$ & $26.1(23.7-29.3)$ & \\
\hline \multicolumn{4}{|l|}{ Diagnosis PAD (Fontaine), $n$} \\
\hline I, Ila/IIb, III & $0,0,0$ & $1,37,2$ & \\
\hline \multicolumn{4}{|l|}{ Medical history, $n$} \\
\hline Diabetes mellitus & 1 & 5 & \\
\hline Hypertension & 13 & 29 & \\
\hline Aspirin intake & 0 & 38 & \\
\hline Anticoagulant intake & 0 & 0 & \\
\hline \multicolumn{4}{|l|}{ Hemostatic variables } \\
\hline Platelet count, $x 10^{9} / \mathrm{L}$ & $255(205-291)$ & $249(213-284)$ & n.s. \\
\hline Mean platelet volume, $f L$ & $10.8(10.2-11.4)$ & $11.1(10.4-11.9)$ & n.s. \\
\hline Hematocrit, $L / L$ & $0.44(0.42-0.47)$ & $0.43(0.39-0.45)$ & n.s. \\
\hline Leukocyte count, $x 10^{9} / \mathrm{L}$ & $6.15(5.60-7.45)$ & $7.50(6.03-9.13)$ & 0.003 \\
\hline D-dimers, $n g / m L$ & $366(259-520)$ & $528(363-835)$ & 0.005 \\
\hline
\end{tabular}


B. For microscopic imaging, an inverted EVOS fluorescence microscope (Life Technology) was used, basically as described elsewhere [28].

Whole-blood thrombus formation under flow was also assayed in real-time using a microfluidics polydimethyl siloxane (PDMS) flow chamber with a straight $1 \mathrm{~mm}$ wide x $50 \mu \mathrm{m}$ height channel, principally as described [33], but without stenosis. The disposable chamber was prepared with a Sylgard 184 kit, by mixing $43 \mathrm{~g}$ of silicone elastomer with $7 \mathrm{~g}$ curing agent (Dow Corning, Wiesbaden, Germany). The degased mixture was poured into a round mold containing water to harden at room temperature. The flow channel inlet and outlet were made using a $3 \mathrm{~mm}$ biopsy punch and a blunt syringe needle, respectively. The flow chip was mounted onto a glass coverslip, coated with collagen type I Horm $(100 \mu \mathrm{g} / \mathrm{mL})$ [34], fixed with a pressure plate, and pre-rinsed. Whole-blood perfusion, using a pulse-free syringe pump (pull mode), was performed as described [35]. Blood samples
(300 $\mu \mathrm{L}$ ) were pre-labeled with $0.5 \mu \mathrm{g} / \mathrm{mL} \mathrm{DiOC}_{6}$ (6975, AnaSpec, San Jose, CA), and flowed at a wall-shear rate of $1600 \mathrm{~s}^{-1}$ for 4 minutes. Microscopic images of deposition of fluorescently labeled platelets were taken as previously described [28], and analyzed for increases in fluorescence.

\section{Microscopic Imaging and Analysis}

Phase-contrast images were analyzed for surface-area-coverage and integrated feature size, using a standardized journal in Metamorph software [36]. Images were also assessed for morphological score from 0 (no platelet adhesion) to 5 (large platelet thrombi) [28]. Fluorescence images of antibody staining were analyzed for surface-area-coverage above background with the program Image J (open access).
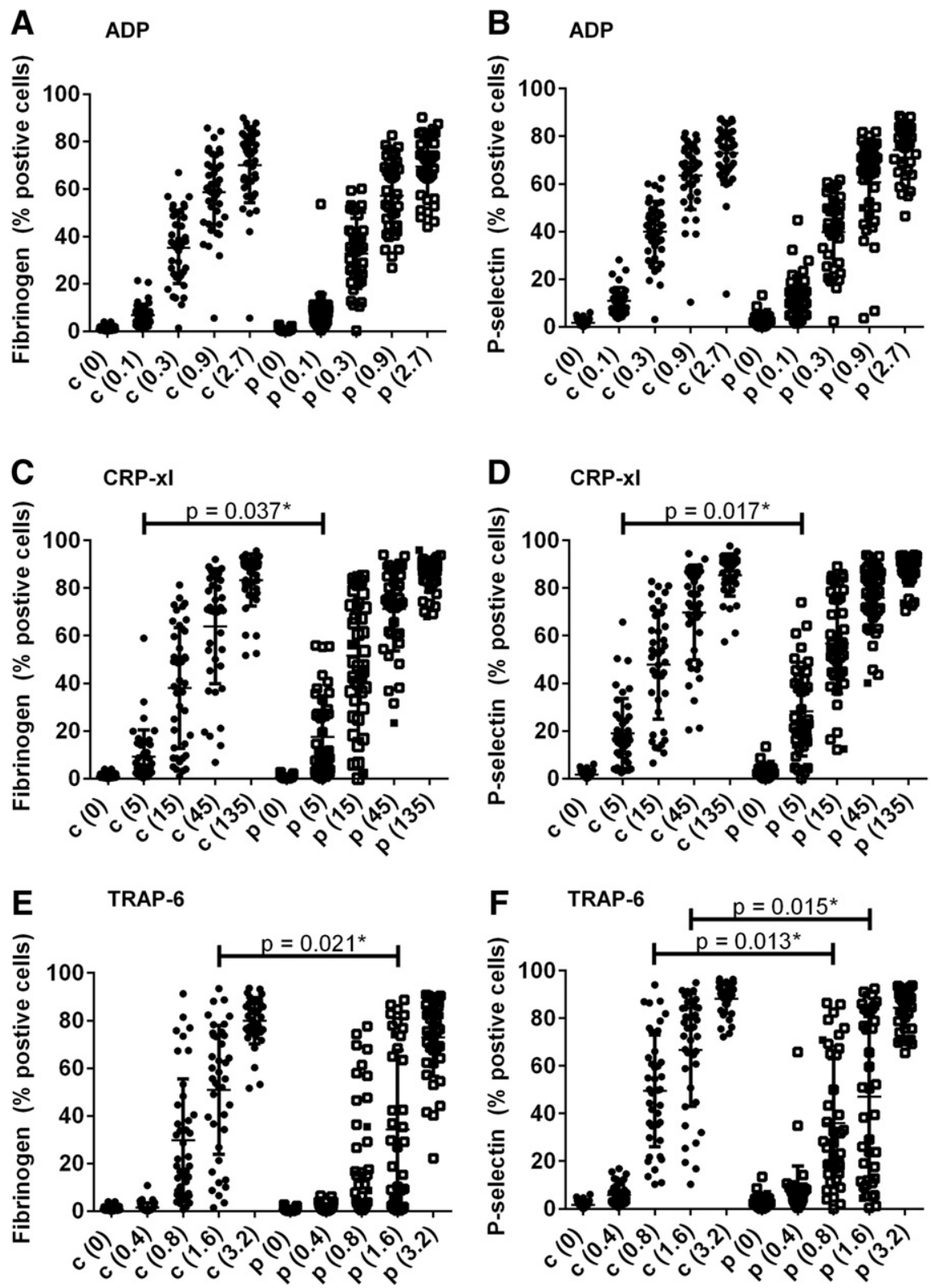

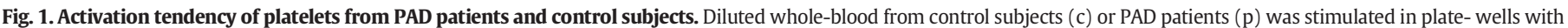

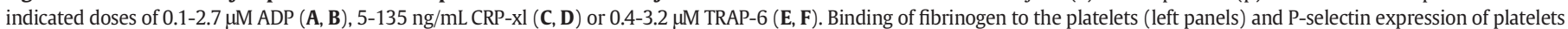

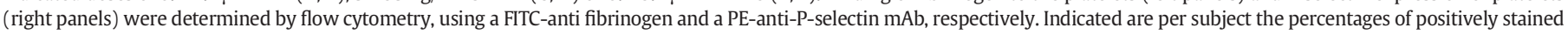
platelets. Patients using aspirin are represented by open squares. Bars indicate mean and S.D. values $(n=40),{ }^{*} P<0.05$. 


\section{Statistics}

Group comparisons were performed using the Mann-Whitney Utest for continuous variables. Assay parameters were compared using the Spearman correlation test. The statistical package for the Social Sciences version 22 was used (SPSS, Chicago, IL). $P$-values $<0.05$ were considered to be significant.

A
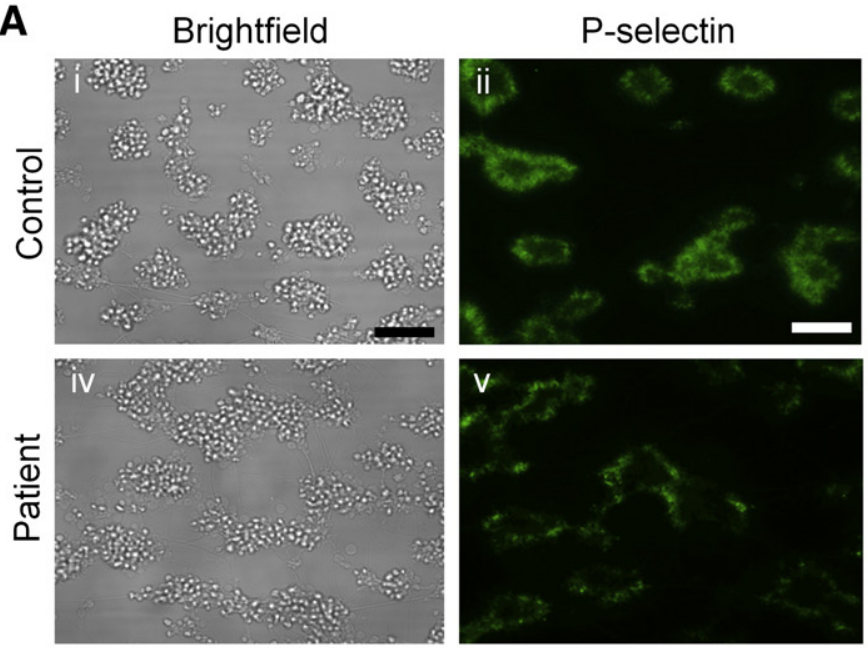

\section{в}
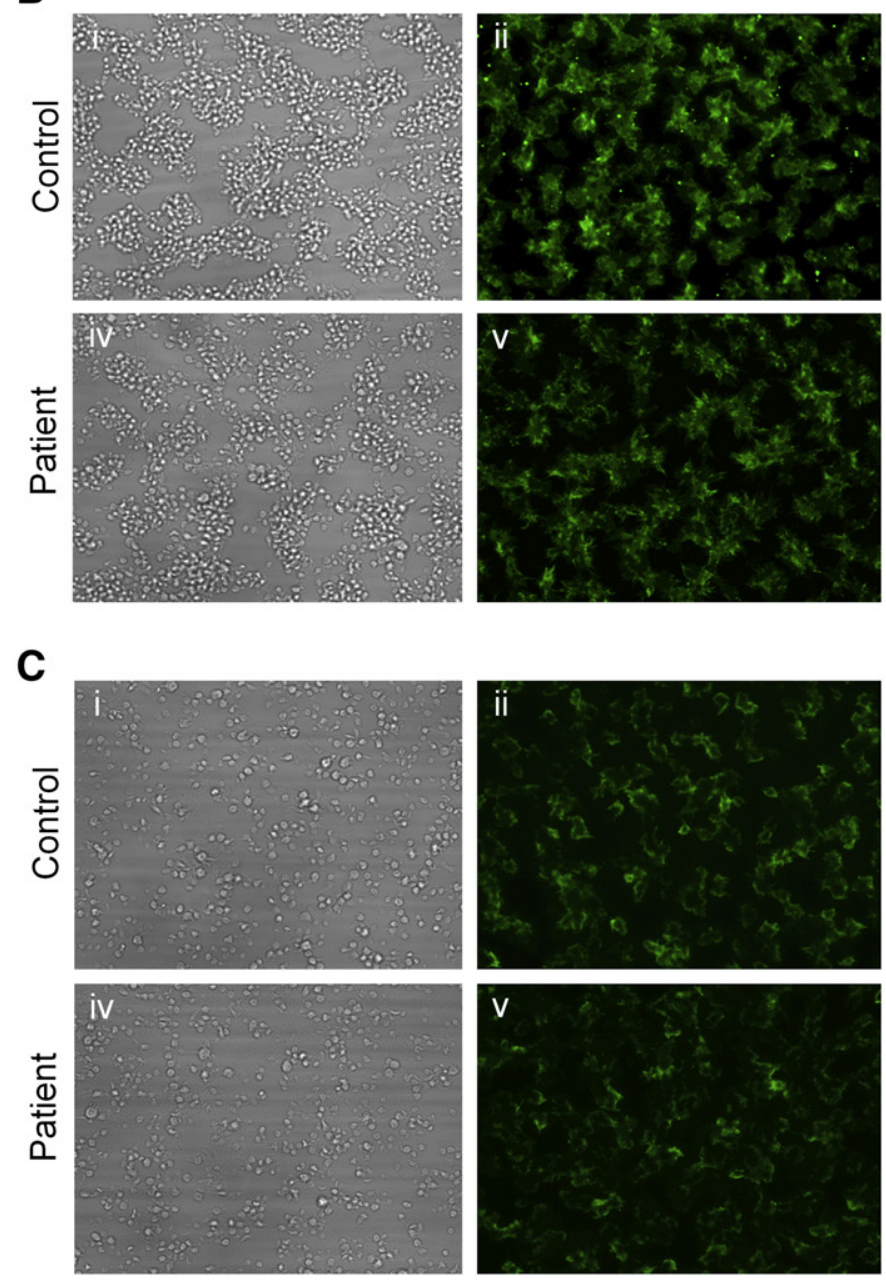

\section{Results}

Undiminished Platelet Activation in Whole-Blood from PAD Patients on Aspirin

Baseline characteristics of the 40 control subjects and 40 PAD patients were comparable for age, gender and body mass index (Table 1). With
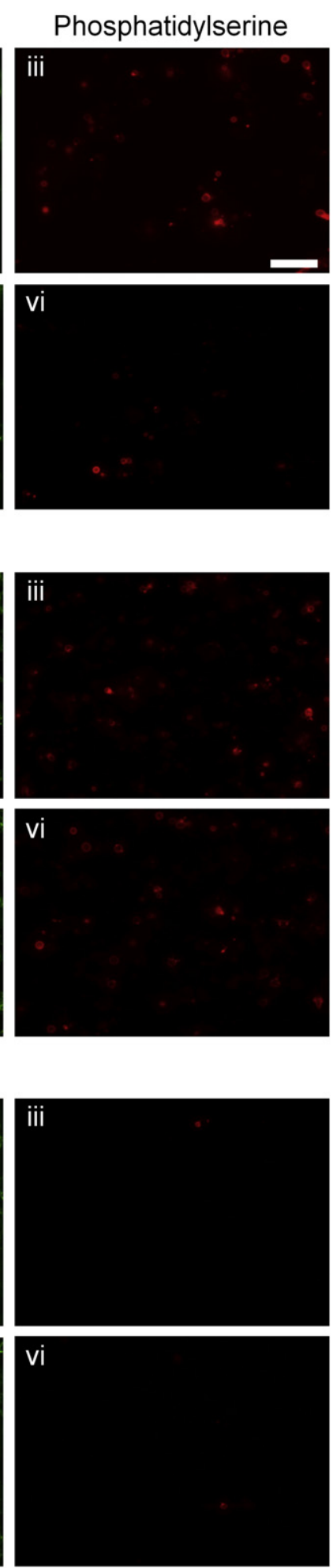

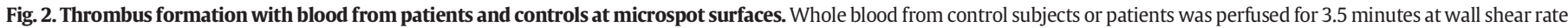

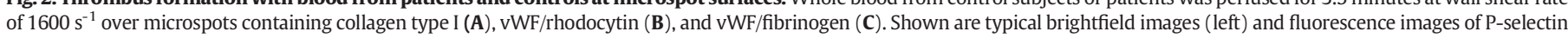
expression (middle) or phosphatidylserine exposure (right) from a representative control subject and patient. Bars $=20 \mu \mathrm{m}$. 
respect to the medical history, the patients ( $v s$. controls) more frequently suffered from diabetes mellitus ( 5 vs. 1 ) and hypertension ( $29 v$ s. 13 ), and in vast majority used prescribed aspirin (38 vs. 0). All patients, and none of the control subjects, were diagnosed as PAD with confirmed Fontaine classification IIa/IIb (37 out of 40). Most hemostatic variables of the PAD patients were in the normal range, but leukocyte counts and plasma levels of the coagulation product, D-dimers, were significantly increased in the patient group (Table 1).

Platelet activation tendency was measured in diluted whole blood samples, using a validated, 96-plate-well-based flow cytometric test, in which both integrin $\alpha_{\text {IIb }} \beta_{3}$ activation and P-selectin exposure are determined in response to dose ranges of the key agonists, ADP (stimulating $\mathrm{P}_{2} \mathrm{Y}_{12} / \mathrm{P}_{2} \mathrm{Y}_{1}$ receptors), $\mathrm{CRP}-\mathrm{xl}$ (stimulating the collagen receptor glycoprotein VI) and TRAP-6 (stimulating the thrombin receptor PAR1) [22]. For various agonists, intra- and inter-individual variation coefficients of the test were $<10 \%$ and $<15 \%$, respectively, for the area under the curve [37].

In response to the weak agonist ADP, platelets from patients and control subjects showed a dose-dependent increase in integrin activation (fibrinogen binding) and limited P-selectin expression (Fig. 1A,

\section{A Morphological score}
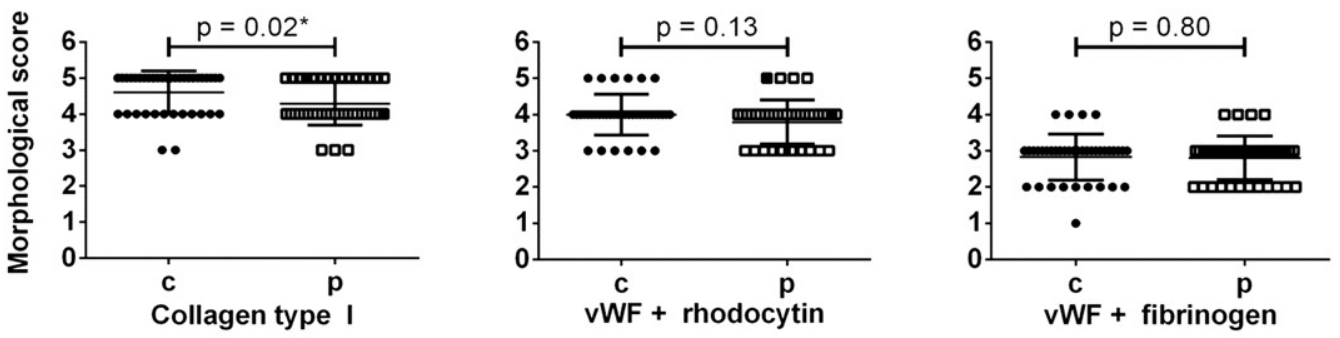

\section{B Platelet deposition}
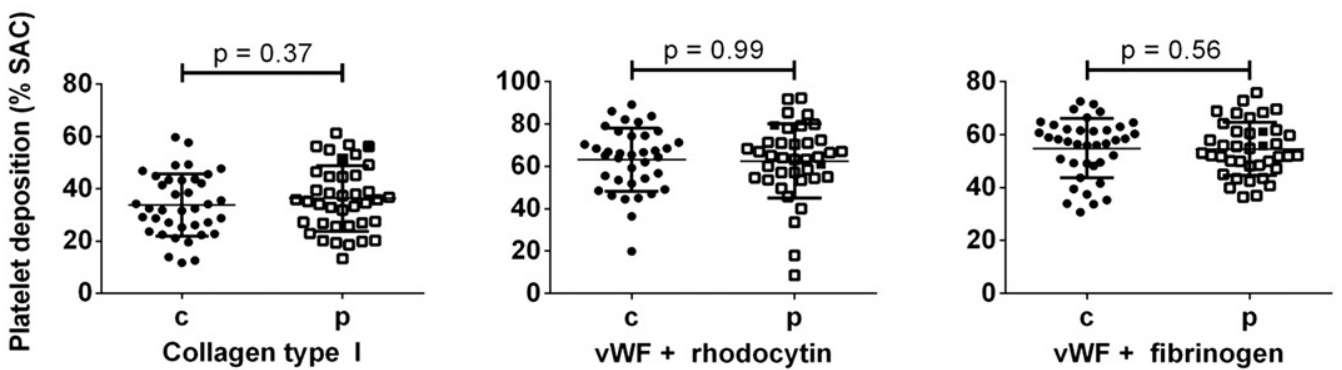

\section{P-selectin}
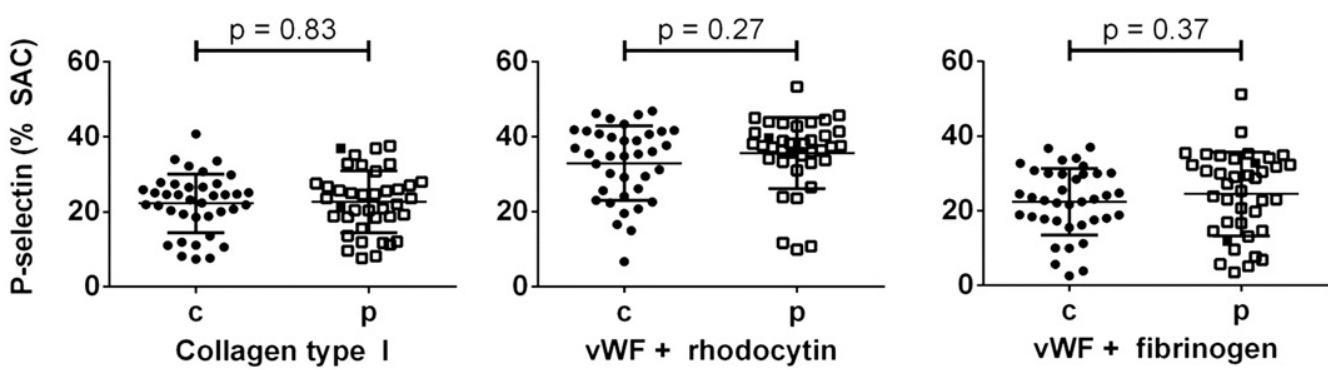

D Phosphatidylserine
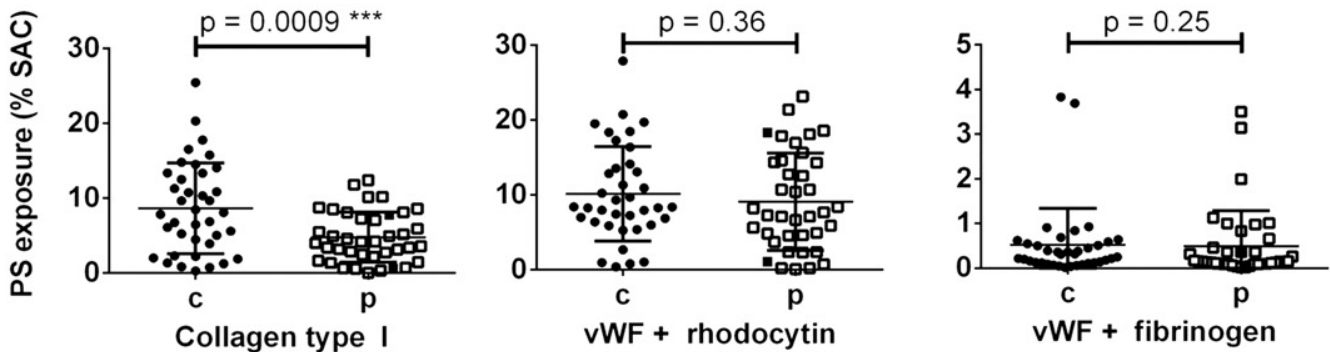

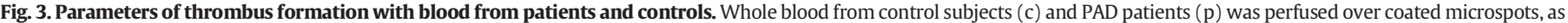

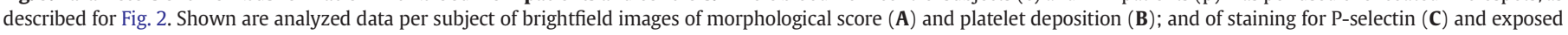
phosphatidylserine (D). Patients using aspirin are represented by open squares. Bars indicate mean and S.D. values $(n=40)$, ${ }^{*} P<0.05$. 
B). Dose-response curves varied per subject but, overall, did not markedly differ between the patient and control groups. Platelet stimulation with CRP-xl (Fig. 1C,D) or TRAP-6 (Fig. 1E,F) resulted in dose-dependent increases in integrin activation and P-selectin expression that, with these stronger agonists, reached maximal levels at high doses. At lower CRP-xl concentrations, both integrin activation and P-selectin expression were significantly higher in the patient group than in the control group $(P \leq 0.037)$, but ranges were overlapping. In contrast, in response to higher doses of TRAP-6, integrin activation $(P=0.021)$ and $P$-selectin expression $(P \leq 0.015)$ were significantly lower in the patient group compared to the controls. Two of the patients did not use aspirin. In blood samples from these patients, agonist-induced integrin activation and P-selectin expression were mostly but not always in the higher ranges (see Fig. 1). Upon stimulation with ADP, no significant effect of aspirin treatments was observed (not shown). This is in agreement with the known sensitivity for aspirin of glycoprotein VI-induced platelet responses [38]. Taken together, these data indicate that, in spite of the use of aspirin, the platelets from PAD patients were in general similarly high in response as the platelets from control subjects, with only reduced activity at high TRAP-6 doses.

\section{Essentially Unchanged Thrombus Formation in Patient Whole Blood}

Whole-blood thrombus formation was tested on three microspots, representing adhesive ligands for major platelet receptors, i.e. collagen type I (activating via glycoprotein VI and integrin $\alpha_{2} \beta_{1}$ ), vWF/ rhodocytin (acting via GPIb and CLEC-2 receptors), and vWF/fibrinogen (acting via GPIb and integrin $\alpha_{\mathrm{IIb}} \beta_{3}$ ). The presence of $\mathrm{vWF}$ (also binding to collagen) allowed thrombus formation to be assessed at high, arterial shear rates [28]. On collagen, large platelet aggregates were formed, staining positively for P-selectin, and individual platelets in the thrombus were present, staining positively with annexin A5 for phosphatidylserine exposure (Fig. 2A), as established before [39]. On vWF/rhodocytin smaller aggregates formed, while staining for Pselectin and phosphatidylserine exposure was still high (Fig. 2B). On vWF/fibrinogen mostly single platelets adhered with P-selectin but no phosphatidylserine exposure (Fig. 2C). Principal assay parameters per surface were obtained following quantitative analysis of the recorded images, according to standard protocols [36]. These were: morphological score, platelet deposition (surface-area-coverage of brightfield images), integrated feature size (weighted cumulative size of platelet aggregates), and extent of P-selectin and phosphatidylserine exposure (Fig. 3A-D). In agreement with earlier assessment of high inter-individual variation of most of these parameters [28], values obtained per subject (controls and patients) showed large differences. Markedly, however, only few differences in these parameters were detected between the patient and control groups. With the patient blood samples, thrombi on collagen were lower in morphological score, integrated feature size and phosphatidylserine exposure $(P \leq 0.02)$. None of the parameters differed for thrombi formed on $\mathrm{vWF} /$ rhodocytin or $\mathrm{vWF} /$ fibrinogen.

Furthermore, real-time imaging of platelet adhesion to collagen using $\mathrm{DiOC}_{6}$-labeled blood samples did not show differences between the control group and patient group (Fig. 4A,B). Similarly, as reported before [28], markers of thrombus formation - per surface and per patient/control sample - were correlated (data not shown). Together, this indicated that for the patient group platelet adhesion, activation and aggregation under flow was mostly unaltered compared to the healthy, control group.

In vitro studies using blood samples from healthy controls were carried out to specifically determine the effect of aspirin on the various assay parameters. As indicated in Fig. 5, on collagen and to a lesser extent on vWF/rhodocytin (morphological score and phosphatidylserine exposure), but not on vWF/fibrinogen, aspirin treatment reduced aspects of thrombus formation. Especially on collagen, thrombus parameters were reduced by more than half.

Comparing the various parameters of collagen-dependent thrombus formation per subject (patients and controls), gave high correlations $\left(P<0.001, r^{2}=0.25-0.56\right.$, Spearman $)$. This compares well with a previous systematic analysis of the thrombus-forming process with blood from healthy subjects [28], and confirms that - in the absence of platelet aberrations - the various platelet activation responses are highly linked. Furthermore, compared per subject, markers of ADP- and collageninduced integrin activation (flow cytometry) strongly correlated with parameters of collagen-dependent platelet aggregation under flow (Table 2), pointing to a subject-dependent activation factor commonly regulating both types of platelet responses.

\section{Discussion}

A recent meta-analysis of randomized trials indicates that in patients with PAD, treatment with aspirin alone led to a statistically insignificant decrease in cardiovascular events, but a significant reduction in nonfatal stroke [40]. Several small-size studies have pointed to high activity of platelets in PAD patients taking aspirin [20,21], which can be reversed by the antiplatelet agent iloprost, a prostacyclin analogue [19]. Here, we used high-throughput whole-blood assays, i.e. multi-agonist testing of platelet activation by flow cytometry and multi-parameter testing of thrombus formation on microarray spots, to determine the platelet activation tendency in 40 patients with PAD receiving aspirin compared to healthy controls not on antiplatelet medication. This systematic analysis points to a general high on-treatment function of the patient platelets in thrombus formation, and thus supports the hypothesis that the
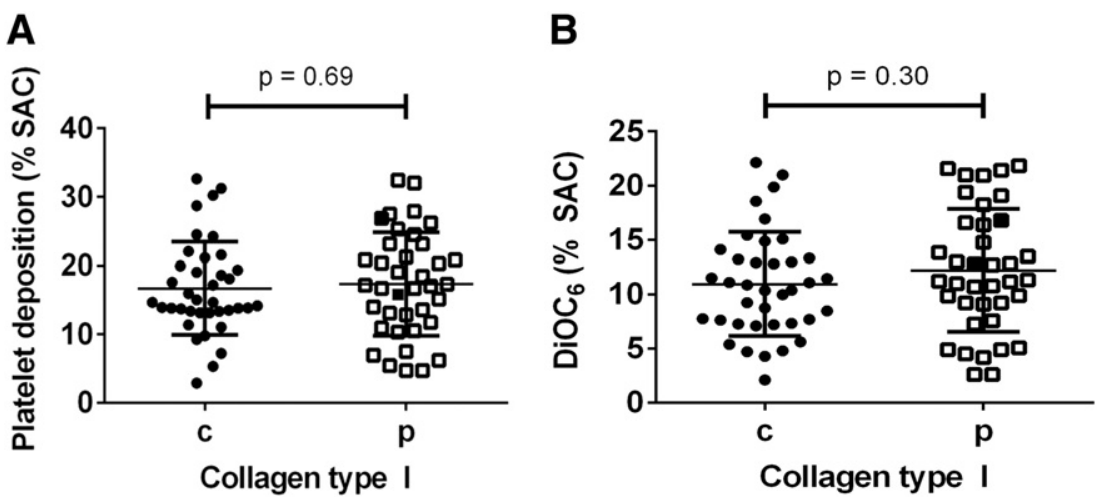

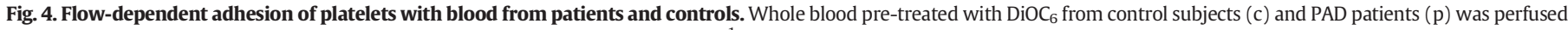

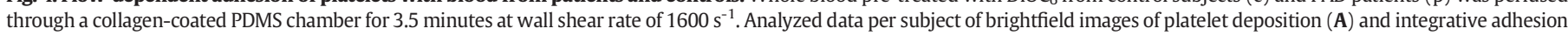
of $\mathrm{DiOC}_{6}$-labeled platelets (B). Patients using aspirin are represented by open squares. Bars indicated mean and S.D. values $(\mathrm{n}=40)$. 


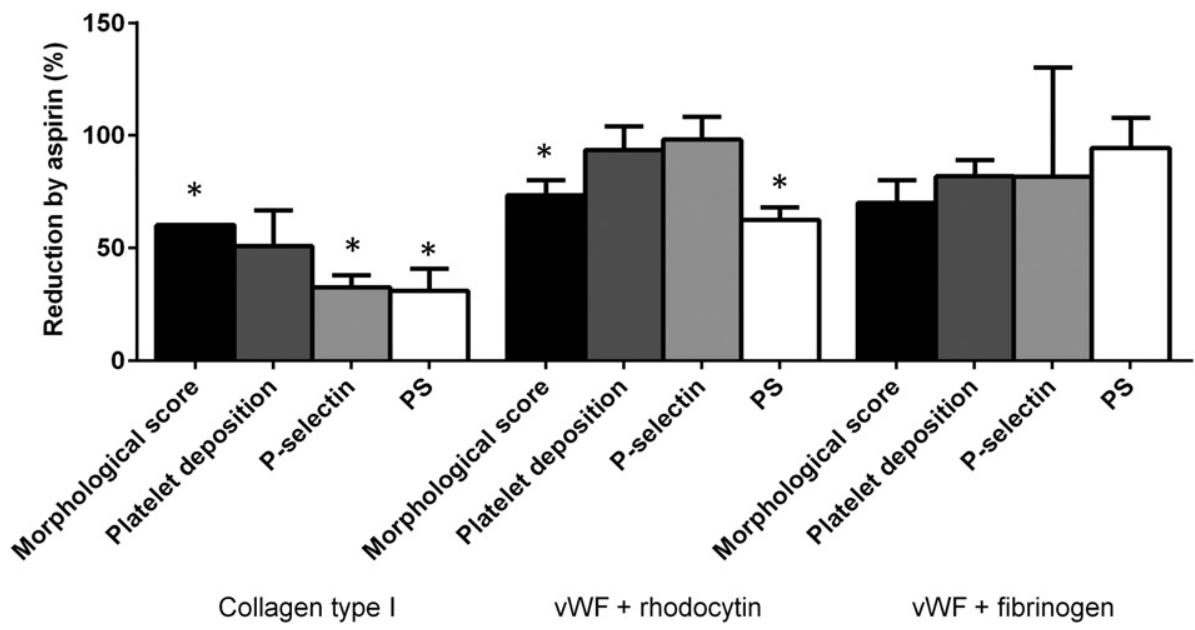

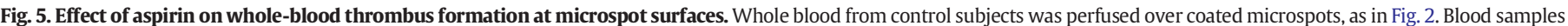

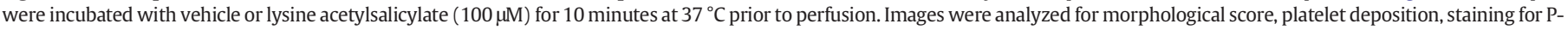
selectin and phosphatidylserine (PS), as described for Fig. 3. Data are expressed as percentages relative to vehicle control. Means \pm S.E.M. $(\mathrm{n}=4)$, ${ }^{*} \mathrm{P}<0.05$.

prothrombotic propensity known for PAD patients is not accompanied by an increased platelet activation profile after intake of aspirin.

In collagen-induced thrombus formation, platelet stimulation via glycoprotein VI and ADP increases the affinity state of integrins $\alpha_{2} \beta_{1}$ and $\alpha_{\mathrm{IIb}} \beta_{3}[41,42]$, and leads to stable platelet adhesion and aggregate

Table 2

Correlations of agonist-induced fibrinogen binding and P-selectin expression with parameters of thrombus formation on collagen microspots. Compared are analyses of platelet deposition (brightfield \% surface area coverage, SAC), aggregate size (integrated feature size IFS), and DiOC $_{6}$ staining. Spearman correlation analysis of data from all subjects $(n=80)$; given are two-sized $\mathrm{P}$ values per flow-cytometric data set. Colour scale from green to white: low to high P values.

\begin{tabular}{|c|c|c|c|c|c|c|}
\hline & \multicolumn{3}{|c|}{ Fibrinogen binding } & \multicolumn{3}{|c|}{ P-selectin expression } \\
\hline Thrombus parameter & SAC & IFS & $\mathrm{DiOC}_{6}$ & SAC & IFS & $\mathrm{DiOC}_{6}$ \\
\hline ADP (0.1) & 0.056 & 0.014 & 0.323 & 0.417 & 0.929 & 0.394 \\
\hline ADP (0.3) & 0.039 & 0.014 & 0.125 & 0.226 & 0.424 & 0.599 \\
\hline ADP (0.9) & 0.016 & 0.007 & 0.058 & 0.096 & 0.232 & 0.239 \\
\hline ADP (2.7) & 0.041 & 0.064 & 0.164 & 0.321 & 0.665 & 0.558 \\
\hline$A D P(A \cup C)$ & 0.033 & 0.008 & 0.202 & 0.243 & 0.361 & 0.664 \\
\hline CRP-xl (5) & 0.007 & 0.011 & 0.058 & 0.346 & 0.336 & 0.466 \\
\hline CRP (15) & 0.012 & 0.020 & 0.012 & 0.104 & 0.198 & 0.882 \\
\hline CRP-xl (45) & 0.083 & 0.050 & 0.066 & 0.393 & 0.219 & 0.310 \\
\hline CRP-xI (135) & 0.072 & 0.083 & 0.107 & 0.579 & 0.805 & 0.627 \\
\hline$C R P-x I(A \cup C)$ & 0.048 & 0.033 & 0.048 & 0.188 & 0.161 & 0.176 \\
\hline TRAP-6 (0.4) & 0.023 & 0.001 & 0.077 & 0.805 & 0.781 & 0.775 \\
\hline TRAP-6 (0.8) & 0.280 & 0.032 & 0.011 & 0.649 & 0.198 & 0.083 \\
\hline TRAP-6 (1.6) & 0.152 & 0.090 & 0.073 & 0.836 & 0.844 & 0.436 \\
\hline TRAP-6 (3.2) & 0.096 & 0.340 & 0.015 & 0.608 & 0.904 & 0.149 \\
\hline TRAP-6 (AUC) & 0.162 & 0.019 & 0.008 & 0.565 & 0.484 & 0.104 \\
\hline $\begin{array}{l}\text { All agonists } \\
(\Sigma A \cup C)\end{array}$ & 0.070 & 0.048 & 0.064 & 0.017 & 0.012 & 0.012 \\
\hline
\end{tabular}

formation [39]. Given that ADP is a primary agonist in establishing stable platelet-platelet interactions under flow [43], the similarity in thrombus formation between the patient and control groups matches the comparable ADP-induced integrin activation (fibrinogen binding) in both groups determined by flow cytometry. This notion is confirmed by the observation that markers of ADP- and collagen-receptor dependent $\alpha_{\text {IIb }} \beta_{3}$ activation (flow cytometry) strongly correlated with markers of the thrombus-forming process on collagen, which is indicative of a common, subject-dependent regulation of both processes.

Although platelet activation and thrombus parameters in the patient group were generally comparable with the control group, there were some typical differences versus the healthy control group. The indication for increased platelet activity in PAD patients came from flow cytometric analysis of platelet activation with low but not high CRP-xl concentrations (stimulating glycoprotein VI). In contrast, decreased activity in the PAD group was observed for TRAP-6-induced platelet activation (stimulating thrombin receptors), which is an aspirin-sensitive response. Furthermore, we found moderate reductions in some (morphological score, phosphatidylserine exposure), but not all (P-selectin and platelet deposition) parameters of thrombus formation on collagen in the patient group. Although these can be explained by the use of aspirin, the effect size appears to be smaller than observed by direct and complete inhibition of control platelets with aspirin in vitro. In agreement with the present results, others have also shown that aspirin markedly affects thrombus formation on collagen under flow $[44,45]$.

The seeming contrasting differences between increased stimulation of patients' platelets with low doses of CPR-xl and reduced parameters of collagen-dependent thrombus formation, can be explained by the fact that, in thrombus formation under flow, not only glycoprotein VI, but also other platelet receptors like integrin $\alpha_{2} \beta_{1}$ and GPIb-V-IX are determinative for this process [46]. This suggests a partly diminished role of these other receptors in the patient group, concerning morphological score and phosphatidylserine exposure on collagen. The effect on phosphatidylserine exposure yet is relevant, because this platelet response is a major trigger of coagulation factor binding and thrombin formation on the platelet surface [47].

Strengths of this study are the relatively large size of the PAD patients (class IIa/IIb) and control groups; the use of well standardized tests using whole blood samples with no platelet activation due to centrifugation steps; and the ability to evaluate multiple platelet activation processes and markers in the same tests. Given the overall consistency of the various assay results, this study may help in improving the management and treatment of PAD, e.g. by considering more effective antithrombotic pharmacoprotection. 


\section{Conflict of Interest}

The authors have declared that no competing interests exist.

\section{References}

[1] Hankey GJ, Norman PE, Eikelboom JW. Medical treatment of peripheral arterial disease. JAMA 2006;295:547-53.

[2] Sartori M, Favaretto E, Legnani C, Cini M, Conti E, Amato A, et al. Thrombophilic risk factors and peripheral arterial disease severity. Thromb Haemost 2010;104:71-7.

[3] Wahlgren CM, Magnusson PK. Genetic influences on peripheral arterial disease in a twin population. Arterioscler Thromb Vasc Biol 2011;31:678-82.

[4] Bennett PC, Silverman SH, Gill PS, Lip GY. Peripheral arterial disease and Virchow's triad. Thromb Haemost 2009;101:1032-40.

[5] Zeymer U, Parhofer KG, Pittrow D, Binz C, Schwertfeger M, Limbourg T, et al. Risk factor profile, management and prognosis of patients with peripheral arterial disease with or without coronary artery disease: results of the prospective German REACH registry cohort. Clin Res Cardiol 2009;98:249-56.

[6] Reininger CB, Graf J, Reininger AJ, Spannagl M, Steckmeier B, Schweiberer L. Increased platelet and coagulatory activity indicate ongoing thrombogenesis in peripheral arterial disease. Thromb Res 1996;82:523-32.

[7] Lowe GD, Rumley A, McMahon AD, Ford I, O'Reilly DS, Packard CJ. Interleukin-6, fibrin D-dimer, and coagulation factors VII and XIIa in prediction of coronary heart disease. Arterioscler Thromb Vasc Biol 2004;24:1529-34.

[8] McDermott MM, Lloyd-Jones DM. The role of biomarkers and genetics in peripheral arterial disease. J Am Coll Cardiol 2009;54:1228-37.

[9] Cooke JP, Wilson AM. Biomarkers of peripheral arterial disease. J Am Coll Cardiol 2010;55:2017-23.

[10] Kleinegris MC, ten Cate H, ten Cate-Hoek AJ. D-dimer as a marker for cardiovascular and arterial thrombotic events in patients with peripheral arterial disease. A systematic review. Thromb Haemost 2013;110:233-43.

[11] Musicant SE, Taylor Jr LM, Peters D, Schuff RA, Urankar R, Landry GJ, et al. Prospective evaluation of the relationship between $\mathrm{C}$-reactive protein, D-dimer and progression of peripheral arterial disease. J Vasc Surg 2006;43:772-80.

[12] Zahavi J, Zahavi M. Enhanced platelet release reaction, shortened platelet survival time and increased platelet aggregation and plasma thromboxane B2 in chronic obstructive arterial disease. Thromb Haemost 1985;53:105-9.

[13] Vanschoonbeek K, Feijge MA, Keuren JF, Coenraad Hemker H, Lodder JJ, Hamulyak K, et al. Thrombin-induced hyperactivity of platelets of young stroke patients: involvement of thrombin receptors in the subject-dependent variability in $\mathrm{Ca} 2+$ signal generation. Thromb Haemost 2002;88:931-7.

[14] Robless PA, Okonko D, Lintott P, Mansfield AO, Mikhailidis DP, Stansby GP. Increased platelet aggregation and activation in peripheral arterial disease. Eur J Vasc Endovasc Surg 2003;25:16-22.

[15] Cassar K, Bachoo P, Ford I, Greaves M, Brittenden J. Platelet activation is increased in peripheral arterial disease. J Vasc Surg 2003;38:99-103.

[16] Galt SW, McDaniel MD, Ault KA, Mitchell J, Cronenwett JL. Flow cytometric assessment of platelet function in patients with peripheral arterial occlusive disease. J Vasc Surg 1991;14:747-55.

[17] Ouriel K. Peripheral arterial disease. Lancet 2001;358:1257-64.

[18] Poredos P, Jezovnik MK, Kalodiki E, Andreozzi GM, Antignani PL, Clement D, et al. Medical management of patients with peripheral arterial disease. Int Angiol 2014.

[19] Lessiani G, Vazzana N, Cuccurullo C, Di Michele D, Laurora G, Sgro G, et al. Inflammation, oxidative stress and platelet activation in aspirin-treated critical limb ischaemia: beneficial effects of iloprost. Thromb Haemost 2011;105:321-8.

[20] Burdess A, Michelsen AE, Brosstad F, Fox KA, Newby DE, Nimmo AF. Platelet activation in patients with peripheral vascular disease: reproducibility and comparability of platelet markers. Thromb Res 2012;129:50-5.

[21] Blann AD, Tan KT, Tayebjee MH, Davagnanam I, Moss M, Lip GY. Soluble CD40L in peripheral artery disease. Relationship with disease severity, platelet markers and the effects of angioplasty. Thromb Haemost 2005;93:578-83.

[22] Roest M, van Holten TC, Fleurke GJ, Remijn JA. Platelet activation test in unprocessed blood (Pac-t-UB) to monitor platelet concentrates and whole blood of thrombocytopenic patients. Transfus Med Hemother 2013;40:117-25.

[23] Goodall AH, Appleby J. Flow-cytometric analysis of platelet-membrane glycoprotein expression and platelet activation. Methods Mol Biol 2004;272:225-53.

[24] van der Meijden PE, Bouman AC, Feijge MA, van Oerle R, Spronk HM, Hamulyak K, et al. Platelet dysfunction in thrombosis patients treated with vitamin $\mathrm{K}$ antagonists and recurrent bleeding. PLoS One 2013;8:e64112.

[25] Ruggeri ZM, Mendolicchio GL. Adhesion mechanisms in platelet function. Circ Res 2007;100:1673-85.
[26] Swieringa F, Kuijpers MJ, Heemskerk JW, van der Meijden PE. Targeting platelet receptor function in thrombus formation: the risk of bleeding. Blood Rev 2014;28: 9-21.

[27] Stegner D, Haining EJ, Nieswandt B. Targeting glycoprotein VI and the immunoreceptor tyrosine-based activation motif signaling pathway. Arterioscler Thromb Vasc Biol 2014;34:1615-20.

[28] de Witt SM, Swieringa F, Cavill R, Lamers MM, van Kruchten R, Mastenbroek T, et al. Identification of platelet function defects by multi-parameter assessment of thrombus formation. Nat Commun 2014;5:4257.

[29] Mota AP, de Castro Santos ME, Lima e Silva F, de Carvalho Schachnik NC, de Oliveira Sousa M, das Gracas Carvalho M. Hypercoagulability markers in patients with peripheral arterial disease: association to ankle-brachial index. Angiology 2009;60: 529-35.

[30] Allison MA, Criqui MH, McClelland RL, Scott JM, McDermott MM, Liu K, et al. The effect of novel cardiovascular risk factors on the ethnic-specific odds for peripheral arterial disease in the Multi-Ethnic Study of Atherosclerosis (MESA). J Am Coll Cardiol 2006;48:1190-7.

[31] Leng GC, Fowkes FG. The Edinburgh Claudication Questionnaire: an improved version of the WHO/Rose Questionnaire for use in epidemiological surveys. J Clin Epidemiol 1992;45:1101-9.

[32] de Witt SM, Swieringa F, Heemskerk JW, Cosemans JM. Multi-parameter assessment of thrombus formation on microspotted arrays of thrombogenic surfaces. Nat Protoc Exch 2014 [http://wwwnaturecom/protocolexchange/protocols/3309].

[33] Westein E, van der Meer AD, Kuijpers MJ, Frimat JP, van den Berg A, Heemskerk JW. Atherosclerotic geometries exacerbate pathological thrombus formation poststenosis in a von Willebrand factor-dependent manner. Proc Natl Acad Sci U S A 2013;110: 1357-62.

[34] Heemskerk JW, Sakariassen KS, Zwaginga JJ, Brass LF, Jackson SP, Farndale RW Collagen surfaces to measure thrombus formation under flow: possibilities for standardization. J Thromb Haemost 2011;9:856-8.

[35] Munnix IC, Gilio K, Siljander PR, Raynal N, Feijge MA, Hackeng TM, et al. Collagen-mimetic peptides mediate flow-dependent thrombus formation by highor low-affinity binding of integrin alpha2beta 1 and glycoprotein VI. J Thromb Haemost 2008;6:2132-42.

[36] Van Kruchten R, Cosemans JM, Heemskerk JW. Measurement of whole blood thrombus formation using parallel-plate flow chambers - a practical guide. Platelets 2012 . 23:229-42.

[37] van Bladel ER, Schutgens RE, Fischer K, de Groot PG, Roest M. Platelet degranulation and glycoprotein IIbIIla opening are not related to bleeding phenotype in severe haemophilia A patients. Thromb Haemost 2014;111:1022-30.

[38] Dawood BB, Wilde J, Watson SP. Reference curves for aggregation and ATP secretion to aid diagnose of platelet-based bleeding disorders: effect of inhibition of ADP and thromboxane A2 pathways. Platelets 2007:18:329-45.

[39] Munnix IC, Strehl A, Kuijpers MJ, Auger JM, van der Meijden PE, van Zandvoort MA et al. The glycoprotein VI-phospholipase Cgamma2 signaling pathway controls thrombus formation induced by collagen and tissue factor in vitro and in vivo. Arterioscler Thromb Vasc Biol 2005;25:2673-8.

[40] Berger JS, Krantz MJ, Kittelson JM, Hiatt WR. Aspirin for the prevention of cardiovascular events in patients with peripheral artery disease: a meta-analysis of randomized trials. JAMA 2009;301:1909-19.

[41] Van de Walle GR, Schoolmeester A, Iserbyt BF, Cosemans JM, Heemskerk JW, Hoylaerts MF, et al. Activation of alphalIbbeta3 is a sufficient but also an imperative prerequisite for activation of alpha2beta1 on platelets. Blood 2007;109:595-602.

[42] Lecut C, Schoolmeester A, Kuijpers MJ, Broers JL, van Zandvoort MA, Vanhoorelbeke $\mathrm{K}$, et al. Principal role of glycoprotein VI in alpha2beta1 and alphallbbeta3 activation during collagen-induced thrombus formation. Arterioscler Thromb Vasc Biol 2004; 24:1727-33.

[43] Cosemans JM, Angelillo-Scherrer A, Mattheij NJ, Heemskerk JW. The effects of arterial flow on platelet activation, thrombus growth, and stabilization. Cardiovasc Res 2013;99:342-52.

[44] Li R, Diamond SL. Detection of platelet sensitivity to inhibitors of COX-1, P2Y(1), and P2Y(1)(2) using a whole blood microfluidic flow assay. Thromb Res 2014;133: 203-10.

[45] Hosokawa K, Ohnishi T, Sameshima H, Miura N, Ito T, Koide T, et al. Analysing responses to aspirin and clopidogrel by measuring platelet thrombus formation under arterial flow conditions. Thromb Haemost 2013;109:102-11.

[46] Siljander PR, Munnix IC, Smethurst PA, Deckmyn H, Lindhout T, Ouwehand WH, et al. Platelet receptor interplay regulates collagen-induced thrombus formation in flowing human blood. Blood 2004;103:1333-41.

[47] Heemskerk JW, Mattheij NJ, Cosemans JM. Platelet-based coagulation: different populations, different functions. J Thromb Haemost 2013;11:2-16. 